\title{
Heel-rise test in the assessment of individuals with peripheral arterial occlusive disease
}

\author{
This article was published in the following Dove Press journal: \\ Vascular Health and Risk Management \\ 22 January 2013 \\ Number of times this article has been viewed
}

\author{
Débora Pantuso Monteiro' \\ Raquel Rodrigues Britto ${ }^{2}$ \\ Ana Clara Ribeiro Lages ${ }^{3}$ \\ Marluce Lopes Basílio 3 \\ Monize Cristine de \\ Oliveira Pires ${ }^{3}$ \\ Maria Luiza Vieira Carvalho' \\ Ricardo Jayme Procópio ${ }^{4}$ \\ Danielle Aparecida Gomes \\ Pereira $^{2}$ \\ 'Rehabilitation Sciences of the \\ Universidade Federal de Minas \\ Gerais, Belo Horizonte-MG, Brazil; \\ ${ }^{2}$ Physiotherapy Department of \\ the School of Physical Education, \\ Physiotherapy and Occupational \\ Therapy of the Universidade Federal \\ de Minas Gerais, Belo Horizonte-MG, \\ Brazil; ${ }^{3}$ Private Practice, Belo \\ Horizonte-MG, Brazil; ${ }^{4}$ Hospital das \\ Clínicas of the Universidade Federal \\ de Minas Gerais, Belo Horizonte-MG, \\ Brazil
}

\begin{abstract}
Introduction: The Heel-Rise Test (HRT) is a clinical instrument relevant to vascular rehabilitation that has been proposed to assess the function of the triceps surae muscle. To use HRT in the assessment of individuals with peripheral arterial occlusive disease (PAOD), its ability to detect differences in the functional performance of patients with PAOD must be verified.
\end{abstract}

Aim: To verify whether the test is sensitive in differentiating between individuals with PAOD with distinct functional capacities.

Materials and methods: A transversal study in which individuals with PAOD were assessed using the HRT, the Walking Impairment Questionnaire (WIQ), and the Shuttle Walk Test. The following variables were analyzed: number of plantar flexions performed in the HRT (time in seconds) and velocity (plantar flexions per second) when performing plantar flexions up to the point of volunteer fatigue, maximum distance walked in the Shuttle Walk Test, and scores obtained in each WIQ domain.

Results: Twenty-five individuals (14 male) were included in the study, with a mean age of $63.36 \pm 9.83$ years. The variables number of plantar flexions and time to perform the HRT were sensitive enough to differentiate between distinct functional capacities in individuals with PAOD ( $P=0.003$ and $P=0.009$, respectively). However, this result was not found for the variable of velocity in the HRT. The number of plantar flexions in the HRT was sensitive enough to differentiate individuals of extreme classes on the WIQ domain, stairs $(P=0.008)$.

Conclusion: The HRT can be applied in clinical practice as a valid assessment of the distinct function capacities of individuals with PAOD.

Keywords: peripheral arterial disease, heel-rise test, walking impairment questionnaire, functional capacity, shuttle walk test

\section{Introduction}

Peripheral arterial occlusive disease (PAOD) is characterized by decreased blood flow secondary to arterial obstruction, mainly in the lower limbs. Atherosclerosis is the most common cause of obstruction. ${ }^{1-9}$ In Brazil, 5.3\% of the individuals aged less than 45 years old have a high probability of developing PAOD. ${ }^{10}$ The study by Makdisse et $\mathrm{al}^{11}$ objectively assessed the prevalence of PAOD, both symptomatic and asymptomatic, in the Brazilian population by measuring the ankle-brachial index and the Edinburgh Claudication Questionnaire. A PAOD prevalence of $10.5 \%$ was found, implying that there are approximately 6 million individuals with PAOD in Brazil after considering that there are 57 million people who share the characteristics of the population assessed in this study. ${ }^{11}$

\footnotetext{
Correspondence: Danielle Aparecida Gomes Pereira

Laboratory of Assessment and Research in Cardiorespiratory Performance, School of Physical Education, Physiotherapy and Occupational Therapy of the Universidade Federal de Minas Gerais Av Antônio Carlos, 6627 - Pampulha, CEP: 31.270-091 - Belo Horizonte-MG, Brazil

$\mathrm{Tel}+553$ I 34094793

Fax + 55 3I 34094783

Email d.fisio@ig.com.br
} 
Intermittent claudication (IC) is the main symptom of PAOD and can be defined as pain, cramping, and pressure or burning in one or both lower limbs, which affects distal or proximal muscle groups. ${ }^{1-5}$ Additionally, IC can reduce individuals' functional capacity and can consequently affect activities of daily living and quality of life..$^{1,12-15}$

As a consequence of the ischemic process, patients with PAOD show adaptations of the contractile tissues of the muscle with resulting deterioration and denervation of the muscle fibers. ${ }^{16}$ These alterations to the muscle fibers reduce muscle strength and thus may worsen functional performance. ${ }^{1,4,13,17}$

The gold standard used for the rehabilitation of individuals with PAOD is to have the individual walk with intensity until they experience a limiting ischemic symptom. This is recognized as a primary strategy to enhance the functional performance of individuals with intermittent claudication. One benefit of walk training is the enhancement of the muscle oxidative capacity with consequent enhancement of functional performance and quality of life. , $18-20^{1,2}$

There are several ways of measuring the functional capacity of individuals with PAOD. The main methods include the 6-minute walking test and the Shuttle Walk Test (SWT). ${ }^{21,22}$ However, these tests do not provide specific information on the muscle performance of the lower limbs observed in these patients.

Adults with PAOD have a smaller transverse section of the triceps surae and less strength in this muscle than individuals who do not have this health condition. ${ }^{23,24}$ Thus, muscle training can be a therapeutic alternative to enhance the functional capacity of individuals with PAOD. ${ }^{15,20,25}$ Considering the muscle alterations observed in these patients and the possible functional repercussions, valid and reliable tests to more specifically assess the muscle performance of individuals with PAOD are necessary. The measurement of muscle strength by an isokinetic dynamometer is valid and reliable; however, use in clinical practice is unlikely because it is a costly method that requires a large amount of physical space and specialized technical training, and it is not a very functional assessment method. ${ }^{26}$

The heel-rise test (HRT) is a clinically relevant instrument used for vascular rehabilitation and is proposed to assess the performance of the triceps surae muscle of individuals with chronic venous insufficiency. ${ }^{27-29}$ The HRT can also be a useful assessment instrument for patients with PAOD because it specifically assesses the triceps surae, the muscle most frequently affected by the disease. ${ }^{23,24}$ The HRT was initially proposed as a unipodal test; ${ }^{27,28}$ however, Pereira et $\mathrm{al}^{30}$ verified that the bipodal test was more reliable because it was influenced less by the individuals' alterations in balance. Moreover, the HRT is a reproducible test that is viable in clinical practice, ${ }^{30}$ and it is able to measure the endurance of the triceps surae in patients with PAOD in both assessment and rehabilitation. The use of the HRT in clinical practice allows for the assessment of the endurance of the main muscle affected in this population given that functional performance may be compromised due to the muscle alterations caused by PAOD. To use the HRT in clinical practice for the assessment of individuals with PAOD, the ability to detect differences in functional performance must be verified. Thus, the aim of this study was to verify whether this test is sensitive in differentiating between distinct functional capacities in individuals with PAOD.

\section{Materials and methods Type of study}

This study was a cross-sectional study in which individuals with PAOD were assessed using the HRT, the SWT, and the Walking Impairment Questionnaire (WIQ).

\section{Participants}

The sample was composed of adults with PAOD recruited from the Support to People with Peripheral Obstructive Arterial Disease Service (Ambulatory Jenny de Andrade Faria, Belo Horizonte, Brazil) or based on diagnosis by angiologists and vascular surgeons from the Hospital das Clínicas of the Federal University of Minas Gerais (UFMG).

Individuals with a diagnosis of PAOD confirmed by the angiology and vascular surgery ambulatory service were selected, independent of age and sex. The inclusion criteria included the following: ankle-brachial index lower than 0.90 at rest; the presence of IC; regular clinical follow-up (that is, at least one medical appointment every 6 months); clinical stability for at least 2 months prior to the study (with no report of presence at an urgency service or hospitalization during this period); no heart failure; and no gait-limiting acute inflammatory diseases, orthopedic or neurologic disorders, history of pulmonary disease, unstable angina, uncontrolled arrhythmias, or adverse health conditions at the moment of the test, such as the flu, a fever, or other conditions.

The volunteers were excluded if they were unable to comprehend and/or perform the procedures; presented with clinical instability; presented with a blood pressure higher than 180/100 $\mathrm{mmHg}$ and heart rate (HR) higher than $120 \mathrm{bpm}$ at rest $;{ }^{31}$ presented with a HR higher than $85 \%$ of the maximum HR predicted for their age during the execution of the test $;{ }^{31}$ or presented with cognitive commitment detected by 
the application of the Mini-Mental State Examination in individuals with an age equal to or greater than 60 years.

\section{Measurements}

All individuals were assessed by a trained examiner, and the tests were performed at the Cardiovascular and Metabolic Rehabilitation of the Ambulatory Jenny de Andrade Faria, of UFMG, in Belo Horizonte. For the performance of the HRT, the reliability of the intra- and interexaminer measurements was assessed. Both intra- and interexaminer reproducibility were high (intraclass correlation coefficient $>0.9$; $P<0.05)$.

The HRT was performed during orthostatism with the individual standing barefoot and with bipodal support. ${ }^{30}$ The individual remained supported by their dominant hand on the wall with the individual's elbow in semiflexion for balance maintenance. An instrument was created so that the individual performed plantar flexion with maximum range across all repetitions. The participant initially performed the first plantar flexion with full range of motion, up until the point that support was required by the metatarsophalangeal joints. Then, the examiner marked the maximum height reached by the participant's head on an adjustable height instrument. The examiner demonstrated to the participant how the test should be executed and oriented the volunteer to lean his/her head on the instrument attached to the wall during every plantar flexion. This was done to guarantee that the individual performed the plantar flexion using full range of motion during every repetition. During the test, the individual performed the maximum number of plantar flexions he/she could bear up until the point of volunteer fatigue, at the fastest velocity possible, and the examiner timed the execution of the test. A verbal command was given at the beginning of the test, and during performance of the test no form of encouragement was given. The examiner registered the number of repetitions performed and the total amount of time required for the execution of the test.

For the performance of the SWT, a 10 meter track marked by two cones with 9 meters between them and another 0.5 meters for the individual to turn further along the track was used. ${ }^{22}$ Initially the examiner explained to the participant how the test should be performed, then, the examiner demonstrated to the volunteer the execution of the first stage of the SWT. The individual was instructed to walk from one cone to the other, according to the rhythm dictated by the sound signals, up to the point of exhaustion, the presence of a limiting symptom, inability to maintain the displacement rhythm, or until a HR greater than $85 \%$ of the maximum predicted was achieved. In the event that the individual did not reach the subsequent cone twice in a row based on the rhythm determined by the sound signals, the test would be interrupted. The examiner gave the standard verbal command at the end of each stage directing the patient to increase his or her velocity.

The WIQ is a questionnaire used to obtain information on the perception and locomotion of individuals with PAOD who have IC. The questionnaire addresses the aspects related to the patient's experiences in the previous month and is composed of three domains: distance (the distance that the individual is able to walk), velocity (the velocity at which the individual is able to walk), and stairs (the number of stairs the individual is able to climb). In a Brazilian sample, the WIQ showed validity and reproducibility after being translated to Portuguese. ${ }^{32}$ Its score varies from $0 \%$ to $100 \%$ in each domain, with $100 \%$ representing the best score.

\section{Procedures}

After reading and signing the written informed consent form, an initial assessment was performed by taking measurements of blood pressure and HR, and of weight and height for the calculation of body mass index. The individuals were questioned about the presence of health conditions and medications used. To characterize the level of physical activity, the Human Activity Profile questionnaire was used.

Patients' clinical and demographic data were collected to characterize the sample. Afterwards, the WIQ was administered as an interview to obtain information on the locomotion ability of the patients with PAOD. The order of performance of the HRT and SWT tests was randomized. The participants were given a 20-minute interval between the performances of each test. Before performance of the subsequent test, the patients' vital signs returned to their baseline values. Blood pressure was checked before and after each test and HR was monitored during the tests with a Polar ${ }^{\circledR}$ cardiofrequencemeter (model S810, Polar Electro, Kempele, Finland). The variables analyzed included the number of plantar flexions performed during the HRT (time in seconds) and velocity (plantar flexions per second) of the execution of the movement up to the point of fatigue experienced by the volunteers, maximum distance walked on the SWT, and score (percentage) in each WIQ domain.

\section{Statistical analysis}

The descriptive analysis is expressed as the measures of tendency and dispersion. To assess the normal dispersion of the data, the Shapiro-Wilk test was used. To verify whether the HRT is sensitive to the distinct functional capacities of individuals with PAOD, two analyses were performed. 
On the main analysis of the present study, a comparison of the results of the HRT between two performance groups in the SWT: maximum distance under 380 meters and maximum distance equal to or over 380 meters. ${ }^{33}$ Pulz et $\mathrm{al}^{33}$ verified that the best cutoff score for the sensitivity and specificity of the maximum distance walked in the SWT that predicted a severe reduction in $\mathrm{VO}_{2 \text { peak }}$ (lower than or equal to $14 \mathrm{~mL} / \mathrm{kg} /$ minute) was 380 meters $(90 \%$ and $87 \%$, sensitivity and specificity respectively). An independent samples $t$-test was conducted to compare the maximum distance achieved in the SWT across the number of plantar flexions and velocity in the HRT. The Mann-Whitney $U$ test was used to compare the maximum distance achieved in the SWT with the amount of time to execution in the HRT.

Afterwards, the following HRT variables were compared among four groups using a one-way analysis of variance based on the results of the WIQ across each domain: Class 1: $<25 \%$; Class 2: $\geq 25 \%$ and $<50$; Class $3: \geq 50 \%$ and $<75 \%$; Class $4: \geq 75 \%$. Across all statistical tests, the significance level was 5\% and Bonferroni adjustments were performed for multiple comparisons. The Statistical Package for the Social Sciences (SPSS 15.0, SPSS, Inc, Chicago, IL, USA) was used to prepare the database and conduct the statistical analysis. The sample calculations were performed after a pilot study was conducted with a minimum of five individuals in each functional group of the SWT. Statistical power of $0.80 \%$ and an alpha of $5 \%$ were considered to estimate the sample size of nine individuals in each functional group.

\section{Results}

All of the individuals reached maximum levels of pain on the triceps surae region during the performance of the HRT. No complications were observed during the performance of the tests. Table 1 presents the characteristics of the patients enrolled in the study.

Table I Participant characteristics (total $\mathrm{n}=25$ )

\begin{tabular}{ll}
\hline Number of males/females (\%) & $14(56 \%) / \mathrm{I}(44 \%)$ \\
Age (years) & $63.36 \pm 9.83$ \\
Body mass (kg) & $68.77 \pm 1 \mathrm{I} .54$ \\
Height $(\mathrm{m})$ & $1.61 \pm 0.09$ \\
BMI $\left(\mathrm{kg} / \mathrm{m}^{2}\right)$ & $26.61 \pm 3.85$ \\
Regular physical activity (\%) & 72 \\
Arterial hypertension (\%) & 80 \\
Diabetes mellitus (\%) & 28 \\
Smokers (\%) & 40 \\
Exsmokers (\%) & 48 \\
ABI at rest & $0.5 \pm 0.14$ \\
\hline
\end{tabular}

Abbreviations: $\mathrm{BMI}$, body mass index; $\mathrm{ABI}$, ankle-brachial index.
With regard to the SWT, the mean maximum walked distance was 352 meters \pm 18.05 meters $(95 \% \mathrm{CI}=314.75$ $389.24)$; $64 \%$ of the individuals walked a distance shorter than 380 meters. The results from the comparison of the HRT variables using the two performance groups in the SWT are shown in Table 2.

The results from the comparison of the HRT variables between the WIQ classes based on distance, velocity, and stairs are shown in Tables 3-5, respectively.

\section{Discussion}

The HRT is an instrument that assesses the function of the calf muscles, which are commonly affected in individuals with PAOD. ${ }^{15,16}$ These muscles play an important role during gait; ${ }^{34}$ hence, individuals with PAOD may present functional capacity deficits, which were objectively assessed in the present study by the SWT and subjectively by the WIQ. ${ }^{1,4,13}$

In the present study, the variables "number of plantar flexions" and "time of execution of the HRT" were sensitive enough to differentiate between distinct functional capacities, as measured by the SWT, in individuals with PAOD. However, this result was not found for the velocity variable on the HRT. The number of plantar flexions on the HRT was also sensitive in differentiating between individuals of classes 1 and 4 on the stairs domain of the WIQ.

Muscle endurance is essential for the execution of activities of daily living and gait because these are long-lasting submaximum activities. The variables, number of plantar flexions and execution time of the HRT, reflect the fatigue endurance of the triceps surae and also the ability of the muscle to resist ischemia caused by arterial obstruction during the activity. Thus, it was expected that such variables would be sensitive in detecting differences in functional performance of individuals with PAOD, compared to the velocity in the HRT.

Table 2 Comparison of the HRT variables between the two performance groups in the SWT

\begin{tabular}{llll}
\hline & $<\mathbf{3 8 0}$ meters & $\begin{array}{l}\geq \mathbf{3 8 0} \text { meters } \\
\mathbf{n = 9}\end{array}$ & $\mathbf{P}$ \\
\hline Number of plantar & $46.5 \pm 21.14$ & $79.55 \pm 29.37$ & $0.003^{*}$ \\
flexions & $(35.23-57.76)$ & $(56.97-102.13)$ & \\
Time & $57.5 \pm 34.37$ & $121.55 \pm 81.2$ & $0.009 *$ \\
& $(39.18-75.8 \mathrm{I})$ & $(59.13-183.98)$ & \\
Velocity & $0.87 \pm 0.25$ & $0.77 \pm 0.27$ & 0.329 \\
& $(0.74-1.00)$ & $(0.56-0.98)$ & \\
\hline
\end{tabular}

Notes: Mean \pm standard deviation and confidence interval. $<380$ meters: distance walked in the SWT $<380$ meters; $\geq 380$ meters: distance walked in the SWT greater than or equal to 380 meters. $* P<0.05$.

Abbreviations: HRT, heel-rise test; SWT, Shuttle Walk Test. 
Table 3 Comparison of the HRT variables between the classes of the WIQ domain distance

\begin{tabular}{|c|c|c|c|c|c|c|}
\hline & $\begin{array}{l}\text { Class I } \\
n=5\end{array}$ & $\begin{array}{l}\text { Class } 2 \\
n=7\end{array}$ & $\begin{array}{l}\text { Class } 3 \\
n=6\end{array}$ & $\begin{array}{l}\text { Class } 4 \\
n=7\end{array}$ & $\mathbf{F}$ & $P$ \\
\hline Number of plantar & $30.6 \pm 12.78$ & $60.14 \pm 26.28$ & $61.66 \pm 29.5$ & $73.71 \pm 29.32$ & 2.73 & 0.07 \\
\hline flexions & $(14.73-46.47)$ & $(35.83-84.45)$ & $(30.7-92.62)$ & $(46.59-100.83)$ & & \\
\hline \multirow[t]{2}{*}{ Time } & $38 \pm 14.2$ & $79.14 \pm 44$ & $76.66 \pm 40.87$ & || $5.7 \mid \pm 96.2$ & 1.63 & 0.21 \\
\hline & $(20.37-55.62)$ & (38.45-I I9.83) & (33.77-I I9.56) & $(26.74-204.68)$ & & \\
\hline \multirow[t]{2}{*}{ Velocity } & $0.81 \pm 0.19$ & $0.82 \pm 0.18$ & $0.84 \pm 0.29$ & $0.87 \pm 0.38$ & 0.05 & 0.99 \\
\hline & $(0.57-1.05)$ & $(0.66-0.99)$ & $(0.53-1.14)$ & $(0.52-1.22)$ & & \\
\hline
\end{tabular}

Notes: Mean \pm standard deviation and $95 \%$ confidence interval. Class I: $<25 \%$; Class 2: $\geq 25 \%$ and $<50$; Class 3 : $\geq 50 \%$ and $<75 \%$; Class $4: \geq 75 \%$.

Abbreviations: HRT, heel-rise test; WIQ, Walking Impairment Questionnaire.

If we compare individuals who walk distances shorter than 380 meters to those who walk distances equal to or greater than 380 meters in the SWT, it is possible to observe a different performance in the HRT in terms of number of plantar flexions and time of execution of the test between both groups. Thus, the primary and secondary variables, number of plantar flexions and time of execution of the HRT, can reflect functional capacity, which is represented by the distance walked in the SWT.

The assessment of fatigue endurance in the triceps surae using the HRT is extremely important for assessing muscle function in patients with PAOD, specifically for monitoring the evolution of the dysfunction or verifying the results of an intervention. Yamamoto et $\mathrm{al}^{35}$ assessed the endurance of the triceps surae muscle in patients with PAOD lying in the supine position. The individual was asked to perform plantar flexion with both limbs simultaneously, with a load of $10 \%$ of his/her body mass. The individual was to perform the plantar flexions at a velocity of 30 repetitions per minute, dictated by a sound signal, up to the point of volunteer fatigue. The aim of the study was to verify the correlation of the results of the plantar flexion test with the results of a treadmill test. The maximum time on the triceps surae endurance test and the distance walked on the treadmill test were strongly correlated $(\mathrm{r}=0.74){ }^{35}$

A pilot study by Pereira et $\mathrm{al}^{17}$ assessed 12 patients with PAOD and verified the correlation between the distance walked in the SWT with the amount of time, in seconds, required to perform five plantar flexions in the HRT. No significant correlation between the distance walked in the SWT and the time required to perform the plantar flexions in the HRT was found. ${ }^{17}$ The time to perform five plantar flexions may not have been enough to provoke the PAOD symptoms in the individual. This result reinforces the importance of performing the HRT until the point of volunteer fatigue, at which point the individual's performance becomes limited by ischemia. Hence, the HRT is able to reflect the muscle's ability to resist ischemia.

We consider the HRT performed at a self-selected velocity, in orthostatism, and with bipodal support up to the point of volunteer fatigue, to be a simpler, more valid, more accessible, safer, and more functional way to assess the endurance of the triceps surae. Moreover, the HRT is sensitive in differentiating between individuals with distinct functional capacities. In the present study, all of the individuals reached maximum ischemic symptoms in the triceps surae during the HRT, demonstrating that the test was able to assess what was proposed.

Walk tests such as the SWT are incremental and induce cardiovascular stress. ${ }^{33}$ Patients with PAOD have a high risk of developing coronary arterial disease and may experience angina during the tests. ${ }^{79}$ The HRT is a safe option because it leads to smaller cardiac overload. In the present study,

Table 4 Comparison of the HRT variables between the classes of the WIQ domain velocity

\begin{tabular}{lllllll}
\hline & Class I & Class 2 & Class 3 & Class 4 & F \\
& $\mathbf{n = 7}$ & $\mathbf{n = 7}$ & $\mathbf{n = 6}$ & $\mathbf{P}$ \\
\hline Number of plantar & $42.86 \pm 25.92$ & $50.28 \pm 23.3$ & $64.5 \pm 27.4$ & $84.2 \pm 28.01$ & 2.812 & 0.064 \\
flexions & $(18.88-66.83)$ & $(28.73-71.84)$ & $(35.74-93.25)$ & $(49.35-119.05)$ & \\
Time & $57.43 \pm 39.76$ & $62.86 \pm 38.6$ & $74 \pm 99.44$ & $145.6 \pm 99.44$ & 2.867 & 0.061 \\
& $(20.65-94.2)$ & $(27.15-98.56)$ & $(30.02-117.98)$ & $(22.12-269.07)$ & & 0.702 \\
Velocity & $0.79 \pm 0.16$ & $0.9 \pm 0.33$ & $0.91 \pm 0.25$ & $0.72 \pm 0.31$ & 0.562 \\
& $(0.64-0.93)$ & $(0.6-1.2)$ & $(0.65-1.17)$ & $(0.34-1.1)$ & & \\
\hline
\end{tabular}

Notes: Mean \pm standard deviation and $95 \%$ confidence interval. Class I: $<25 \%$; Class 2: $\geq 25 \%$ and $<50$; Class 3: $\geq 50 \%$ and $<75 \%$; Class $4: \geq 75 \%$.

Abbreviations: HRT, heel-rise test; WIQ, Walking Impairment Questionnaire. 
Table 5 Comparison of the HRT variables between the classes of the WIQ domain stairs

\begin{tabular}{|c|c|c|c|c|c|c|}
\hline & $\begin{array}{l}\text { Class I } \\
n=6\end{array}$ & $\begin{array}{l}\text { Class } 2 \\
n=3\end{array}$ & $\begin{array}{l}\text { Class } 3 \\
n=4\end{array}$ & $\begin{array}{l}\text { Class } 4 \\
n=12\end{array}$ & $\mathbf{F}$ & $P$ \\
\hline $\begin{array}{l}\text { Number of plantar } \\
\text { flexions }\end{array}$ & $\begin{array}{l}34 \pm 13.17 \\
(20.17-47.83)\end{array}$ & $\begin{array}{l}54.66 \pm 20.03 \\
(4.9-104.43)\end{array}$ & $\begin{array}{l}43.25 \pm 20.15 \\
(11.18-75.32)\end{array}$ & $\begin{array}{l}76.58 \pm 27.8 I^{*} \\
(58.9 I-94.26)\end{array}$ & 5.219 & 0.008 \\
\hline Time & $\begin{array}{l}41.5 \pm 17.05 \\
(23.6-59.39)\end{array}$ & $\begin{array}{l}68.66 \pm 46.11 \\
(-45.88 \text { to } 183.21)\end{array}$ & $\begin{array}{l}48.75 \pm 15.17 \\
(24.6-72.89)\end{array}$ & $\begin{array}{l}I \mid 3.66 \pm 74.43 \\
(66.38-160.95)\end{array}$ & 2.784 & 0.066 \\
\hline Velocity & $\begin{array}{l}0.84 \pm 0.2 \\
(0.62-1.05)\end{array}$ & $\begin{array}{l}0.91 \pm 0.32 \\
(0.12-1.7)\end{array}$ & $\begin{array}{l}0.86 \pm 0.18 \\
(0.58-1.14)\end{array}$ & $\begin{array}{l}0.8 I \pm 0.31 \\
(0.6 I-I .0 I)\end{array}$ & 0.121 & 0.947 \\
\hline
\end{tabular}

Notes: Mean \pm standard deviation and $95 \%$ confidence interval. Class I: $<25 \%$; Class $2: \geq 25 \%$ and $<50$; Class 3 : $\geq 50 \%$ and $<75 \%$; Class $4: \geq 75 \%$. $* P<0.05$ comparing I versus 4.

Abbreviations: HRT, heel-rise test; WIQ, Walking Impairment Questionnaire.

no complications were observed during the HRT. Yamamoto etal ${ }^{35}$ observed that the triceps surae endurance test generates overload in this muscle, which is similar to that generated by the treadmill test, with a smaller effect on the cardiovascular system. Furthermore, this study verified that eleven individuals (41\%) developed nonclaudicating symptoms (dyspnea and chest discomfort) during the treadmill test alone. ${ }^{35}$ Due to the impossibility of performing a walking test in individuals with PAOD, the HRT may be used in clinical practice.

In the present study, the number of plantar flexions in the HRT was sensitive for differentiating between individuals of extreme classes in the stairs domain on the WIQ, demonstrating the relationship between the functional alterations and subjective perceptions of one's ability to climb stairs.

The study by Jain et $\mathrm{al}^{36}$ verified that men and women with PAOD who have a lower score on the stairs domain of the WIQ present with a higher risk of mortality due to cardiovascular diseases or other causes when compared to those patients with higher scores in this same domain. Furthermore, the score on the stairs domain of the WIQ provides additional data on the mortality risks due to other causes and cardiovascular diseases beyond the data given by the ankle-brachial index obtained in an initial assessment. ${ }^{36}$ These results demonstrate that the WIQ is already regarded as an instrument that is sensitive in detecting differences across the functional capacity and mortality risk of individuals with PAOD.

When the WIQ classes were compared, differences between classes 1 and 4 were detected. The lack of differences between classes 1, 2, and 3 might be explained by the small sample size in classes 2 and 3 . The sample size calculation was done among the SWT classes, and scores on the WIQ were defined as the secondary outcomes. Thus, future studies are required to detect whether HRT is clinically relevant in differentiating between individuals with PAOD who present with distinct functional capacities as measured by the WIQ.

A limitation of the present study is the discrepancy between the proportion of individuals who walked a maximum distance in the SWT that was shorter than 380 meters (64\%) and the proportion of individuals who walked a maximum distance in the SWT longer than or equal to 380 meters (36\%); this may have partially compromised data generalization and analysis.

Additional studies are necessary to establish normative values of the HRT, which can be used as a point of comparison in future studies across different clinical situations involving the assessment of healthy individuals and patients with specific health conditions.

\section{Conclusion}

The variables number of plantar flexions and time required to execute the HRT were sensitive enough to differentiate between the distinct functional capacities of individuals with PAOD. Thus, the HRT can be used in clinical practice as a valid assessment of individuals with PAOD who have distinct functional capacities.

\section{Acknowledgments}

This study received financial support from the Institutional Program of Research Grants for Newly Engaged Doctors of the Pro-Rectory of Research of the Universidade Federal de Minas Gerais (PRPQ/UFMG). This study was also supported by the CNPq (Conselho Nacional de Desenvolvimento Científico e Tecnológico - Grant 307597/2011-3) and the FAPEMIG (Fundação de Amparo à Pesquisa do estado de Minas Gerais - PPM-00072-09).

\section{Disclosure}

The authors report no conflicts of interest in this work. 


\section{References}

1. Hiatt WR, Regensteiner JG, Wolfel EE, Carry MR, Brass EP. Effect of exercise training on skeletal muscle histology and metabolism in peripheral arterial disease. J Appl Physiol. 1996;81(2):780-788.

2. Ouriel K. Peripheral arterial disease. Lancet. 2001;358(9289):1257-1264.

3. Golledge J. Lower-limb arterial disease. Lancet. 1997;350(9089): 1459-1465.

4. Levy PJ. Epidemiology and pathophysiology of peripheral arterial disease. Clin Cornerstone. 2002;4(5):1-15.

5. Cimminiello C. PAD. Epidemiology and pathophysiology. Thromb Res. 2002;106(6):V295-V301.

6. Guidon M, McGee H. Exercise-based interventions and health-related quality of life in intermittent claudication: a 20-year (1989-2008) review. Eur J Cardiovasc Prev Rehabil. 2010;17(2):140-154.

7. Hamburg NM, Balady GJ. Exercise rehabilitation in peripheral artery disease: functional impact and mechanisms of benefits. Circulation. 2011;123(1):87-97.

8. Parmenter BJ, Raymond J, Fiatarone Singh MA. The effect of exercise on haemodynamics in intermittent claudication: a systematic review of randomized controlled trials. Sports Med. 2010;40(5):433-447.

9. Salameh MJ, Ratchford EV. Update on peripheral arterial disease and claudication rehabilitation. Phys Med Rehabil Clin N Am. 2009;20(4): 627-656.

10. Nascimento MR. Doença arterial obstrutiva periférica (DAOP) [webpage on the Internet]. Transdoreso Associação dos Pacientes Doadores e Transplantados Renais de Sorocaba e Região: Sorocaba, Brazil. Available from: http://www.transdoreso.org/estudo_cardiologia.shtml. Accessed June 18, 2012. Portuguese.

11. Makdisse M, Pereira AC, Brasil DP, et al. Prevalência e fatores de risco associados à doença arterial periférica no projeto corações do Brasil. Arq Bras Cardiol. 2008;91(6):402-414. Portuguese.

12. Gardner AW, Montgomery PS, Killewich LA. Natural history of physical function in older men with intermittent claudication. J Vasc Surg. 2004;40(1):73-78.

13. Faxon DP, Fuster V, Libby P, et al; for American Heart Association. Atherosclerotic Vascular Disease Conference: Writing Group III: pathophysiology. Circulation. 2004;109(21):2617-2625.

14. Norgren L, Hiatt WR, Harris KA, Lammer J; for TASC II Working Group. TASC II section F on revascularization in PAD. J Endovasc Ther. 2007;14(5):743-744.

15. Regensteiner JG, Wolfel EE, Brass EP, et al. Chronic changes in skeletal muscle histology and function in peripheral arterial disease. Circulation. 1993;87(2):413-421.

16. McGuigan MR, Bronks R, Newton RU, et al. Muscle fiber characteristics in patients with peripheral arterial disease. Med Sci Sports Exerc. 2001;33(12):2016-2021.

17. Pereira DAG, Faria BMA, Gonçalves RAM, et al. Relação entre força muscular e capacidade funcional em pacientes com doença arterial obstrutiva periférica: um estudo piloto. Jornal Vascular Brasileiro. 2011;10(1):1-5. Portuguese.

18. Gardner AW, Poehlman ET. Exercise rehabilitation programs for the treatment of claudication pain. A meta-analysis. JAMA. 1995;274(12): 975-980.

19. Regensteiner JG, Steiner JF, Hiatt WR. Exercise training improves functional status in patients with peripheral arterial disease. JVasc Surg. 1996;23(1):104-115.
20. Hiatt WR, Wolfel EE, Meier RH, Regensteiner JG. Superiority of treadmill walking exercise versus strength training for patients with peripheral arterial disease. Implications for the mechanism of the training response. Circulation. 1994;90(4):1866-1874.

21. ATS Committee on Proficiency Standards for Clinical Pulmonary Function Laboratories. ATS statement: guidelines for the six-minute walk test. Am J Respir Crit Care Med. 2002;166(1):111-117.

22. Singh SJ, Morgan MD, Scott S, Walters D, Hardman AE. Development of a shuttle walking test of disability in patients with chronic airways obstruction. Thorax. 1992;47(12):1019-1024.

23. McDermott MM, Hoff F, Ferrucci L, et al. Lower extremity ischemia, calf skeletal muscle characteristics, and functional impairment in peripheral arterial disease. J Am Geriatr Soc. 2007;55(3):400-406.

24. McDermott MM, Tian L, Ferrucci L, et al. Associations between lower extremity ischemia, upper and lower extremity strength, and functional impairment with peripheral arterial disease. J Am Geriatr Soc. 2008;56(4):724-729.

25. McDermott MM, Ades P, Guralnik JM, et al. Treadmill exercise and resistance training in patients with peripheral arterial disease with and without intermittent claudication: a randomized controlled trial. JAMA. 2009;301(2):165-174.

26. Perrin DH. Isokinetic Exercise and Assessment. Champaign, IL: Human Kinetics Publishers; 1993.

27. Svantesson U, Osterberg U, Grimby G, Sunnerhagen KS. The standing heel-rise test in patients with upper motor neuron lesion due to stroke. Scand J Rehabil Med. 1998;30(2):73-80.

28. Lunsford BR, Perry J. The standing heel-rise test for ankle plantar flexion: criterion for normal. Phys Ther. 1995;75(8):694-698.

29. van Uden CJ, van der Vleuten CJ, Kooloos JG, Haenen JH, Wollersheim H. Gait and calf muscle endurance in patients with chronic venous insufficiency. Clin Rehabil. 2005;19(3):339-344.

30. Pereira DAG, Oliveira KL, Cruz JO, Souza CG, Cunha-Filho I. Avaliação da reprodutibilidade de testes funcionais na doença arterial periférica. Revista Fisioterapia e Pesquisa. 2008;15:228-234. Portuguese.

31. Thompson WR, Gordon NF, Pescatello LS. Diretrizes do ACSM para os Testes de Esforço e sua Prescrição 2010. Rio de Janeiro: Ganabara Koogan; 2010. Portuguese.

32. Ritti-Dias RM, Gobbo LA, Cucato GG, et al. Translation and validation of the walking impairment questionnaire in Brazilian subjects with intermittent claudication. Arq Bras Cardiol. 2009;92(2):136-149.

33. Pulz C, Diniz RV, Alves AN, et al. Incremental shuttle and six-minute walking tests in the assessment of functional capacity in chronic heart failure. Can J Cardiol. 2008;24(2):131-135.

34. Perry J. Análise de Marcha: função normal e patológica. São Paulo: 2005. Portuguese.

35. Yamamoto K, Miyata T, Onozuka A, Koyama H, Ohtsu H, Nagawa H. Plantar flexion as an alternative to treadmill exercise for evaluating patients with intermittent claudication. Eur J Vasc Endovasc Surg. 2007;33(3):325-329.

36. Jain A, Liu K, Ferrucci L, et al. The Walking Impairment Questionnaire stair-climbing score predicts mortality in men and women with peripheral arterial disease. J Vasc Surg. 2012;55(6):1662-1673. e2.

Vascular Health and Risk Management

\section{Publish your work in this journal}

Vascular Health and Risk Management is an international, peerreviewed journal of therapeutics and risk management, focusing on concise rapid reporting of clinical studies on the processes involved in the maintenance of vascular health; the monitoring, prevention and treatment of vascular disease and its sequelae; and the involvement of

metabolic disorders, particularly diabetes. This journal is indexed on PubMed Central and MedLine. The manuscript management system is completely online and includes a very quick and fair peer-review system, which is all easy to use. Visit http://www.dovepress.com/ testimonials.php to read real quotes from published authors. 